\title{
Advance directives: advancement for palliative care in Brazil
}

\section{Keywords: advance directive, physicians, health care}

\section{Mini review}

The Advance Directive (AD), under the name of Living Will, was proposed by attorney Louis Kutner in the late 1960s in the United States. Its purpose was to discuss the conflicting situations of end-oflife between the doctor and the patient, especially that which is related to their choices and their acceptance of certain treatments, in order to preserve their autonomy.

Despite more than 50 years of existence of the AD, in Brazil the discussions around this subject are still recent. Only starting from 2012, with Resolution no. 1995 of the Federal Medical Council, which deals with $\mathrm{AD}$, has this controversial and multifaceted issue begun to be discussed more frequently among health care professionals, reaching the lay population due to its repercussion in the media.

In this resolution, the $\mathrm{AD}$ is defined as: The set of wishes, previously and expressly manifested by the patient, about the care and treatment that he or she wants to receive when he or she is unable to freely and autonomously express their will. ${ }^{1}$ It states that the individual may choose to record the medical treatments he or she does not wish to receive in certain situations in the future, to appoint a power of attorney to make decisions for him when he is no longer competent to do so, or both. It is important to emphasize that the resolution has normative power only for physicians and, therefore, does not take into account other professionals, thus it stimulates the debate on the subject, especially with regard to its legislative regulation and clarification concerning the rights of people with advanced diseases to express their wishes. ${ }^{2}$

The $\mathrm{AD}$ was born in response to the scientific and technological advances of the twentieth century, which, despite collaborating to improve the quality of life and increase human longevity, have contributed to stigmatizing death, which instead of being something natural has begun to be seen as an enemy to be defeated at any cost. ${ }^{3}$ As in other cultures, the themes involving death and finitude are still considered taboos in Brazil. Even in the face of the exponential increase in life expectancy of the Brazilian population, the change in the morbidity and mortality profile of the population, the chronicity of the diseases, and the longer period of living with the dying process that has occurred in the last decades, there are still difficulties in addressing this issue.

With protective intent, health professionals, family members and patients tend to avoid talking about finitude and death. On the one hand, caregivers feel that talking about it can increase the pain of the individual, make him or her depressed, and make him suffer. The patient, in turn, in order to protect his family or loved ones, also avoids addressing the subject. In this way, a scenario of emotional isolation is gradually created, in which the parties involved have similar, but not shared, feelings, doubts, and longings. This situation, known as a conspiracy of silence, contributes to the denial of death, makes it difficult to express the desires of those who are at the end of
Volume 2 Issue I - 2018

Maria Inês Nunes, Monica Martins Trovo
Post-graduate in Bioethics, Universidade Santo Amaro, Brazil

Correspondence: Maria Inês Nunes, post-graduate in Bioethics, Universidade Santo Amaro, Rua Aimbere, 2.039, CEP 01258-020, São Paulo/SP, Brazil, Email minesnunes I8@gmail.com

Received: January 12, 2018 | Published: January 31, 2018

life and, consequently, the planning and execution of tasks that make it possible to experience this process with dignity. It may even result in the therapeutic obstinacy that ends up depriving the person of a dignified death. ${ }^{4}$

A decent death is one of the foundations of $\mathrm{AD}$, therefore this instrument can contribute to the planning of care at the end of life, as it helps the patient to reflect on his illness, to discuss with their families and the health team about their concerns, values, and desires regarding the dying process. Patients should have time to consider and reconsider, and change if necessary or reverse their decision. ${ }^{5}$

Although the heart of the $\mathrm{AD}$ is the exercise of autonomy, the patient cannot be abandoned to elaborate this document without the due clarification of its terms and without knowing and discussing the details, possibilities, and expected outcomes. Patients need to be properly instructed on the procedures that will be performed in order to fulfill their choices. ${ }^{6}$ Whether or not they go to the hospital, whether or not to start a treatment need to be discussed with the health team and family members. This is because care will be performed by these actors in a detailed and synchronized manner, and therefore need to be understood from the perspective of the therapeutic plan and the specifications of the patient. Good clinical practice implies respect for the wishes and values of the patient, within the limits legally established. ${ }^{7}$ In caring for an end-of-life person, one should bear in mind not only the ethical and moral principles established that involve attention, but also the interpersonal relationship in which emotional, cultural, and spiritual aspects should be heard, considered, and valued.

In the Brazilian reality, however, the management of information about diagnosis and prognosis is still a neuralgic point. Patients, especially of the less favored classes, are unaware of their situation and even if they receive information, they often do not understand them due to technical language and are afraid to question the doctor. Thus, they do not exercise their autonomy, since they do not know their rights as users of health services, adopting a position of resignation and compliance.

Due to these interfering elements, it is necessary to develop mechanisms to eliminate or minimize them and to avoid that the $\mathrm{AD}$ becomes just a bureaucratic exercise. ${ }^{5}$ This is a real risk in the Brazilian scenario, where palliative care is still little disseminated among the population in terms of knowledge and access. Although they are consolidated as a practice of care in other countries, in Brazil 
this modality has been in existence for more than 20 years and is still in its infancy.

According to data recently released at scientific meetings of the National Academy of Palliative Care, there are currently only 123 services that offer palliative care in the country, with $58 \%$ of these institutions located in the richest states of the federation and mostly in hospitals. In a country of 207 million inhabitants, distributed heterogeneously in an area of 8.5 million $\mathrm{km}^{2}$, this scenario is alarming.

Unfortunately, palliative care is still not an option available to most Brazilians. Faced with the low supply of specialized services or teams, people with life threatening diseases or who are in the final stages of their natural aging process end up using hospitals and emergency rooms as referral services. And that is precisely why AD can be so relevant to the advancement of the palliative philosophy in Brazil. The increase in its use in Brazil following the resolution that regulates it underscores the population's search for change in this scenario and brings out the importance of discussing its use in the practice of health professionals. Thus, it is important to draw up and implement strategies and legislation in Brazil that will allow the AD to be used to assist and to give a voice to people in their dying process. ${ }^{8}$

\section{Acknowledgements}

None.

\section{Conflict of interest}

The author declares no conflict of interest.

\section{References}

1. CFM. Resolução n 1995. Dispõe sobre as diretivas antecipadas de vontades dos pacientes. Conselho Federal de Medicina, Diário Oficial da União, Brasília: Springer; 2012 pp. 260-270.

2. Dadalto L. Diretivas antecipadas de vontade. Rev. Brasileira de Bioética. 2013;21(3):463-476.

3. Esslinger I. O paciente, a equipe de saúde e o cuidador: de quem é a vida, afinal? In: Pessini L, et al. editors. Humanização e cuidados paliativos. Ciência \& Saúde Coletiva. 2004;10(3):319.

4. Nunes MI, Anjos MF. Diretivas antecipadas de vontade: benefícios, obstáculos e limites. Rev Bioét. 2014;22(2):241-251.

5. Hui EC. The living will-pitfalls, benefits and a way forward. Hong Kong Med J.2007;13(6):493-495.

6. Kovács MJ. Bioética nas questões da vida e da morte. Psicologia USP. 2003;14(2):115-117.

7. Bermejo JC, Belda RM. Testamento vital: diálogo sobre la vida. lamuerte y lalibertad. Madrid, Spain: Springer; 2011. 121 p.

8. Nunes Maria Inês. Leitura bioética analítica do testamento vital em seu processo de elaboração por sujeitos concretos. Centro Universitário São Paulo, Brazil: Springer; 2014. 212 p. 